\title{
Auditory Evoked Potential Mismatch Negativity in Normal-Hearing Adults
}

\author{
Laura Flach Schwade $^{1}$ Dayane Domeneghini Didoné ${ }^{2}$ Pricila Sleifer $^{1}$ \\ ${ }^{1}$ Department Human Health and Communication, Universidade \\ Federal do Rio Grande do Sul - UFRGS, Ringgold Standard Institution, \\ Porto Alegre, Rio Grande do Sul, Brazil \\ 2 Postgraduate Program in Child and Adolescent Health, UFRGS, Porto \\ Alegre, Rio Grande do Sul, Brazil \\ Address for correspondence Laura Flach Schwade, Speech-Language \\ Pathologist, Departamento de Saúde e Comunicação Humana da \\ UFRGS, Universidade Federal do Rio Grande do Sul, Ramiro Barcelos, \\ 2600, Santa Cecília, Porto Alegre/RS Porto Alegre, Rio Grande do Sul \\ 90040-060, Brazil (e-mail: laura_fs_@hotmail.com).
}

\begin{abstract}
Keywords

- evoked auditory potentials

- electrophysiology

- event-related potential

- evoked potentials

- auditory

- evoked potentials

Introduction Mismatch Negativity (MMN) corresponds to a response of the central auditory nervous system.

Objective The objective of this study is to analyze MMN latencies and amplitudes in normal-hearing adults and compare the results between ears, gender and hand dominance.

Methods This is a cross-sectional study. Forty subjects participated, 20 women and 20 men, aged 18 to 29 years and having normal auditory thresholds. A frequency of $1000 \mathrm{~Hz}$ (standard stimuli) and $2000 \mathrm{~Hz}$ (deviant stimuli) was used to evoked the MMN. Results Mean latencies in the right ear were $169.4 \mathrm{~ms}$ and $175.3 \mathrm{~ms}$ in the left ear, with mean amplitudes of $4.6 \mu \mathrm{V}$ in the right ear and $4.2 \mu \mathrm{V}$ in the left ear. There was no statistically significant difference between ears. The comparison of latencies between genders showed a statistically significant difference for the right ear, being higher in the men than in women. There was no significant statistical difference between ears for both right-handed and left-handed group. However, the results indicated that the latency of the right ear was significantly higher for the left handers than the right handers. We also found a significant result for the latency of the left ear, which was higher for the right handers.

Conclusion It was possible to obtain references of values for the MMN. There are no differences in the MMN latencies and amplitudes between the ears. Regarding gender, the male group presented higher latencies in relation to the female group in the right ear. Some results indicate that there is a significant statistical difference of the MMN between right- and left-handed individuals.
\end{abstract}

\section{Introduction}

The auditory assessment comprises an investigation of the peripheral and central auditory nervous system. Alterations in the peripheral auditory system correspond to hearing loss, while those in the central auditory nervous system reflect the central auditory processing disorder which is related to detection, discrimination and interpretation of sound

received

March 10, 2016

accepted

June 18, 2016

published online

September 2, 2016 10.1055/s-0036-1586734. ISSN 1809-9777. stimuli. ${ }^{1,2}$ This central auditory processing disorder can be investigated through Auditory Evoked Potentials (AEPs). This assessment is recommended by ASHA, ${ }^{3}$ which emphasizes the use of the Long Latency Auditory Evoked Potentials (LLAEP). The LLAEP represent the brain activity and correspond to the cognitive and the central auditory process. ${ }^{4,5}$

The Mismatch Negativity (MMN) is one of the LLAEP and reflects an electrical cerebral response of the processing,
Copyright $\odot 2017$ by Thieme Revinter

Publicações Ltda, Rio de Janeiro, Brazil
License terms

(®) $\Theta \circledast$ 
discrimination, and auditory memory abilities. ${ }^{6,7}$ The main generator of the MMN is the auditory cortex, but the frontal cortex, thalamus, and the hippocampus also contribute to the response. ${ }^{8}$ The MMN is elicited by the detection of changes in a series of standard stimuli. This detection indicates a disagreement (mismatch) between the new auditory sensorial input in relation to a standard stimulus stored in the shortterm auditory sensorial memory. The MMN is a note with negative polarity (negativity) present in the record of such potential. ${ }^{1,7,9}$

The most important feature is that the MMN can be recorded without influence of the subject's attention and with no task requirements, which make it particularly appropriate for a clinical study in different populations, especially in the evaluation of infants, toddlers, children with difficulties of attention, and for central auditory processing disorders. $^{5,10,11}$ In addition, the MMN can provide an objective measure of overall brain degeneration and the functional state of the brain, contributing to informing of the patient's clinical conditions in other medical areas, such as psychiatry (regarding patients suffering from schizophrenia, epilepsy and those under the effect of drugs), ${ }^{12-14}$ and in neurology (individuals with multiple sclerosis, the elderly, and comatose patients). ${ }^{15-18}$

The MMN is a negative deflection that occurs after the P2 response - a positive peak of the LLAEP which occurs around $160 \mathrm{~ms}^{7}$ According to the literature, ${ }^{6,8}$ the MMN is identified as the maximum negative deflection range from 100 to $250 \mathrm{~ms}$. This potential is obtained by subtracting the responses for the standard stimuli from the deviant stimuli. The latency and the amplitude are the most important parameters to identify the possible auditory processing disorders. $^{7,8}$

The MMN can be obtained using several stimuli such as pure tone, including its variations (frequency, duration, and intensity), and by complex stimuli, including speech (phonemic differences, spatial location, and partial omission). 7,11,19 The MMN response can be determined by the attention to the stimulus rather than its frequency and intensity. For this reason, the best results can be achieved when the subject ignores the auditory stimuli presented, directing her attention to more interesting stimuli, that is, watching a video, viewing a book, playing a game in the computer or tablet, among others. ${ }^{1,5,20}$

The MMN is a promising tool for the assessment of the auditory function, including diagnosis, monitoring, and prognosis of the auditory rehabilitation process. Nevertheless, the investigation of the MMN in normal-hearing and without disorders of the central auditory processing is necessary to understand the normal auditory process in the brain. 1,17,20

There is a gap in the literature of studies on the values of latency and amplitude of the MMN for normal subjects. Some researchers conclude that further studies on the MMN are necessary to standardize the values of latency and amplitude to make the MMN effectively performed in clinical practice. ${ }^{1,5,17}$ A study with normal-hearing adults of both sexes found reference values for the MMN latency in the range of $150.70 \mathrm{~ms}$ and $184.0 \mathrm{~ms}$, and amplitude between $1.435 \mu \mathrm{V}$ and
$3.548 \mu \mathrm{V} .^{1}$ Another research with older adults found MMN latency values in the range of $148.67 \mathrm{~ms}$ to $171.0 \mathrm{~ms}$ and amplitude between $1.847 \mu \mathrm{V}$ and $2.753 \mu \mathrm{V},{ }^{17}$ while other surveys with the MMN in children reported latency ranges between $150 \mathrm{~ms}$ to $250 \mathrm{~ms} .^{11,21}$

Thus, given the great importance and applicability in audiological practice and to contribute to the few national and international studies on the MMN findings in normalhearing subjects, the purpose of this study was to analyze the responses of MMN amplitudes and latencies in normalhearing individuals aged between 18 and 29 years of both sexes, and also to compare the MMN findings between ears, gender, and hand dominance with the results found in the scientific literature.

\section{Methods}

This research is characterized as an observational, crosssectional, contemporary, and individual study. The convenience sample consisted of individuals of both genders, with normal-hearing, aged between 18 and 29 years. The Scientific Committee and Research Ethics Committee evaluated and approved the project (protocol $n^{\circ} .44969115 .8 .1001 .5334$ ).

Still emphasizing the completeness of Resolution 466/12 which deals with human research, only the individuals who have signed the Informed Consent participated of this study. All subjects were informed about the methodology, risks, discomfort and the confidentiality of data.

The sample size was calculated, considering a significance level of 0.05 , a statistical power of $90 \%$, and an effect size of 0.7 (moderate) (EpiInfo - Statcal, CDC, Atlanta, U.S.A.). The software estimated a sample size of 38 individuals.

We conducted the study in an electrophysiology clinic of a university in Rio Grande do Sul and included individuals with normal hearing thresholds, aged between 18 and 29 years, with high school graduation, and without history of diagnosis of auditory system dysfunction, that is, auditory diseases. We excluded from study individuals with genetic abnormalities, history of neurological diseases, intellectual disability or other cognitive changes, and who did not understand the procedures.

The information about age, gender, level of education, illness, hand dominance, among others, were obtained through anamnesis. After this, all subjects were evaluated by the Pure Tone Audiometry, Speech Recognition Index (SRI), Speech Recognition Threshold (SRT), Acoustic Emittance Measurements and the Mismatch Negativity (MMN). Furthermore, we also examined the external auditory canal.

We performed the Pure Tone Audiometry through a previously calibrated model Harp Inventis audiometer (Inventis, Padova, Italy). The test took place in a soundproof booth by air conduction in the frequencies of $250,500,1000$, $2000,3000,4000,6000$, and $8000 \mathrm{~Hz}$, and bone conduction in the frequencies of 500,1000, 2000, 3000, and $4000 \mathrm{~Hz}$. The classification of hearing level was made with the Davis and Silverman classification (1970). ${ }^{22}$

The SRI and the SRT took place within the same situation and using the same equipment, but just by air conduction in 
both ears. We performed SRI with 25 monosyllabic words, which were presented in a comfortable intensity (40dBNA -decibel hearing level- above the tri-tone average for air conduction in the frequencies of 500,1000 , and $2000 \mathrm{~Hz}$ ) in each ear. The individuals were asked to repeat the words. The initial intensity to perform the SRT was also 40dBNA above the tri-tone average for air conduction. The intensity was reduced until reaching the intensity level at which the patient could understand and repeat $50 \%$ of the tri-syllabic words presented.

We conducted the Acoustic Emittance Measurements with the Impedance Audiometer AT235h (Interacoustics A/S, Middelfart, Denmark). We obtained the Tympanometry curves through a probe of $226 \mathrm{~Hz}$, inserted into the entrance of the individual's external ear canal. We investigated the Static and dynamic complacencies, and classified the curve according to Jerger (1970). ${ }^{23}$ We obtained the acoustic reflexes with the same equipment for the frequencies of 500,1000, 2000, and $4000 \mathrm{~Hz}$. We performed the assessment from ipsilateral and contralateral in both ears.

The MMN was performed in an acoustically and electrically treated room with the equipment MASBE ATC Plus (Contronic, Pelotas, Brasil). The individual was positioned in a comfortable chair with headrest. The skin was cleaned with a Nuprep exfoliating cleanser and gauze. The electrodes were fixed with electrolytic paste (Ten 20 conductive) and adhesive tape. The ground electrode was placed on the forehead (Fz); the active electrode was placed close to the scalp (Fpz); and the references electrodes were placed in the right and left mastoid (M2, M1). The earphones (Earphone TONE $\left.{ }^{\mathrm{TM}} \mathrm{GOLD}\right)$ were inserted in both ears. The impedance was lower than $5 \Omega$ in each derivation, and the difference between the electrodes did not exceed $2 \Omega$. We performed an electroencephalogram scan (EEG) to detect spontaneous electrical activity in the brain, to verify artifacts that could interfere in the test. The examiner was instructed to maintain the participants relaxed and not cross legs and arms.

The type of auditory stimulus used was the tone burst. The stimuli were presented in monaural mode, but both ears were assessed. We used a frequency of $1000 \mathrm{~Hz}$ (standard stimuli) and $2000 \mathrm{~Hz}$ (deviant stimuli) to evoke the MMN. The stimuli were presented with 50 cycles, speed of 1.8 stimuli per second, polarity alternate, intensity of 70 to $90 \mathrm{dBNA}$, highpass filter of $1 \mathrm{~Hz}$, low-pass filter of $20 \mathrm{~Hz}$, Notch - Yes, acquisition full scale of $200 \mu \mathrm{V}, 95 \%$ of noise limit. The window of analyses was of $500 \mathrm{~ms}$ and amplitude of $7.5 \mu \mathrm{V}$. We presented the stimuli in an oddball paradigm, using $90 \%$ of standard stimuli and $10 \%$ of deviant stimuli. The equipment allowed 2000 promediations, but we stopped the assessment at least at 150 for each individual.

We gave individuals information about the test and, to deviate attention from the auditory stimuli, they received instructions to watch a quiet movie on the tablet. Two evaluators/audiologists analyzed all results at different times.

The database was made on an Excel program and analyzed by SPSS (Statistical Package for Social Sciences), version 20.0. The level of statistical significance was $5 \%$ ( $p \leq 0.05$ ). Continuous variables were described as mean, standard deviation, minimum and maximum, and the categorical variables were presented by absolute and relative frequencies. We used the Kolmogorov-Smirnov test for data distribution. We used the Student $t$-test to compare the variable ears when the data presented as a symmetric distribution, and the Wilcoxon test when the distribution was asymmetric. The comparison for the continuous variables between right- and left-handed individuals were made with Student $t$-test for the independent groups (symmetric data distribution) or the Mann Whitney U-test (asymmetric data distribution). Considering the casuistic, we compared all results based on the mean of the variables.

\section{Results}

Forty-four individuals participated in the study. Were excluded four of them, who did not meet the eligibility criteria or did not complete the proposed procedures. Thus, the results refer to a sample of 40 participants. Descriptive data are described in -Table 1.

The information relating to the latencies and amplitudes of the MMN in the ears are shown in - Table 2 and - Fig. 1. There was no statistically significant difference between the ears.

The comparison of latencies of the MMN between genders showed a statistically significant difference for the right ear, being higher in male than in female. This difference did not occur for the left ear and for the comparison between amplitudes in both groups (- Table 3 and -Fig. 2).

The latencies and amplitudes for right and left ear were compared with the individuals' hand dominance (-Table 4). There was no significant statistical difference between ears for both the right-handed and left-handed group.

For the comparison between the right and left handers for each ear, the results indicated that the latency of the right ear was significantly higher for the left handers than the right handers. the latency of the left ear also presented a significant result, which was higher for the right handers. These differences were not found for the amplitude.

Table 1 Descriptive measures for gender, age and hand dominance

\begin{tabular}{|l|l|l|}
\hline \multirow{2}{*}{ Variables } & \multicolumn{2}{l|}{$\begin{array}{l}\text { Total sample } \\
(\boldsymbol{n}=\mathbf{4 0})\end{array}$} \\
\cline { 2 - 3 } & $\mathrm{N}$ & $\%$ \\
\hline Gender & 20 & 50.0 \\
\hline Female & 20 & 50.0 \\
\hline Male & \multicolumn{2}{|}{} \\
\hline Age (years) & $22.3 \pm 2.9$ \\
\hline $\begin{array}{l}\text { Mean value } \pm \text { standard } \\
\text { deviation (Minimum/Maximum) }\end{array}$ & $(18-29)$ \\
\hline Hand dominance & 36 & 90.0 \\
\hline Right-handed & 4 & 10.0 \\
\hline Left-handed
\end{tabular}


Table 2 Comparison for latency and amplitude of MMN between ears

\begin{tabular}{|c|c|c|c|c|c|}
\hline \multirow[t]{2}{*}{ Variables } & \multicolumn{5}{|c|}{ Descriptive measures $(n=40)$} \\
\hline & Mean value & Standard deviation & Minimum & Maximum & $\mathrm{p}$ \\
\hline \multicolumn{6}{|c|}{ Latency (ms) } \\
\hline RE & 169.4 & 51.6 & 92.5 & 308.2 & \multirow[t]{2}{*}{$0.278 £$} \\
\hline $\mathrm{LE}$ & 175.3 & 54.0 & 107.6 & 351.1 & \\
\hline \multicolumn{6}{|c|}{ Amplitude $(\mu \mathrm{V})$} \\
\hline RE & 4.6 & 4.5 & 1.0 & 23.3 & \multirow[t]{2}{*}{$0.562 \S$} \\
\hline $\mathrm{LE}$ & 4.2 & 3.8 & 1.0 & 19.7 & \\
\hline
\end{tabular}

Abbreviations: $\mu \mathrm{V}$, microvolt; LE, left ear; ms, milliseconds; RE, right ear.

$\mathrm{E}$ : Test t-Student for paired data; $\S$ : Test Wilcoxon. Level of statistical significance: $p<0.05$.

\section{Discussion}

In our research, we investigated the MMN in normal hearing adults over 18 years old due to the maturity of the central auditory nervous system. The age group is important considering that the MMN achieves the optimum value of latency and amplitude during school age. ${ }^{24,25}$ Also, it is known that the presbycusis may start in the age of $30,{ }^{26}$ so this sample consisted of individuals aged up 29. Besides the care with the aged, the number of the sample in this study was higher than others in the scientific literature, regarding the standardization of MMN.,17

The MMN is automatically generated in the auditory and frontal cortex from a change in discriminating of the auditory stimulus. ${ }^{8}$ In this study the $1000 \mathrm{~Hz}$ was used as being the standard stimuli and the $2000 \mathrm{~Hz}$ the deviant stimuli. Other studies consider that deviations of up to $10 \%$ are effective in producing the MMN. The big differences in the stimuli are not recommended due to the possibility of overcoming the P3, which can compromise the MMN record. ${ }^{16}$ In this study and in other scientific researches, $1,27,28$ the MMN was found in all participants even with a difference of over $10 \%$ among the stimuli presented.

In the present study, the mean latency of the MMN in normal-hearing subjects was of $169.4 \mathrm{~ms}$ in the right ear (RE) and $175.3 \mathrm{~ms}$ in the left year (LE). The mean amplitudes were of $4.6 \mu \mathrm{V}$ in the RE and $4.2 \mu \mathrm{V}$ in the LE (-Table 2 and - Fig. $\mathbf{1}$ ). These results are similar to those preconized by the scientific literature as normal MMN, with latencies ranging from $100 \mathrm{~ms}$ to $250 \mathrm{~ms}$ and amplitudes around $3 \mu \mathrm{V}$. $^{1,7,17,20,29}$ The standardization of these values of MMN are important because the abnormal responses can suggest functional or anatomical changes in the auditory and frontal cortex, which are related with cognitive abilities. ${ }^{30}$ Furthermore, the results from this research did not show differences of latencies and amplitudes between the ears, agreeing with others studies. $^{17,31}$

In this study, the results of the latencies and amplitude of the MMN between genders showed a significant difference in the RE. The mean latencies were $187.6 \mathrm{~ms}$ for the men and $151.1 \mathrm{~ms}$ for the women (-Table 3 and -Fig. 2). These differences between groups were not found for the LE ( $188.1 \mathrm{~ms}$ for men and $162.6 \mathrm{~ms}$ for women). These results corroborate with other studies about the MMN standardization in adults, ${ }^{1}$ which also found a significant statistical difference between gender, but in both ears: the cited authors found mean latency values of the MMN of $153.2 \mathrm{~ms}$ in the RE in the women and $150.7 \mathrm{~ms}$ in the LE; in the men, $184.0 \mathrm{~ms}$ in the RE and $170.4 \mathrm{~ms}$ in the LE.
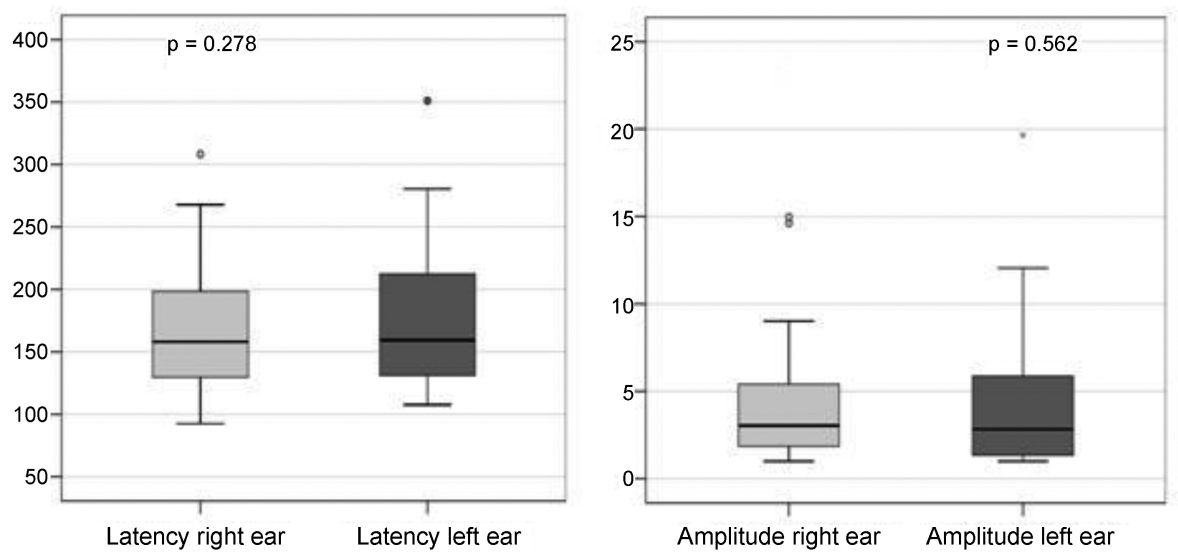

Fig. 1 Box-Plot. Distribution of amplitude and latency values in both ears. 
Table 3 Comparison for latency and amplitude of MMN according to ears and gender

\begin{tabular}{|c|c|c|c|c|c|c|}
\hline \multicolumn{2}{|c|}{ Variables and sex } & \multicolumn{5}{|c|}{ Descriptive measures $(n=40)$} \\
\hline & & Mean value & Standard deviation & Minimum & Maximum & $\mathrm{p}$ \\
\hline \multicolumn{7}{|c|}{ Latency (ms) } \\
\hline \multirow[t]{2}{*}{ RE } & Female & 151.1 & 41.1 & 92.5 & 242.6 & \multirow[t]{2}{*}{$0.024 ¥$} \\
\hline & Male & 187.6 & 55.4 & 112.7 & 308.2 & \\
\hline \multirow[t]{2}{*}{$\mathrm{LE}$} & Female & 162.6 & 41.0 & 107.6 & 261.5 & \multirow[t]{2}{*}{$0.140 ¥$} \\
\hline & Male & 188.1 & 62.9 & 116.5 & 351.1 & \\
\hline \multicolumn{7}{|c|}{ Amplitude $(\mu \mathrm{V})$} \\
\hline \multirow[t]{2}{*}{ RE } & Female & 4.1 & 3.2 & 1.0 & 15.0 & \multirow[t]{2}{*}{$0.862 ¥$} \\
\hline & Male & 5.1 & 5.5 & 1.0 & 23.3 & \\
\hline \multirow[t]{2}{*}{$\mathrm{LE}$} & Female & 4.4 & 4.4 & 1.0 & 19.7 & \multirow[t]{2}{*}{$0.883 ¥$} \\
\hline & Male & 3.9 & 3.2 & 1.0 & 12.1 & \\
\hline
\end{tabular}

Abbreviations: $\mu \mathrm{V}$, microvolt; LE, left ear; ms, milliseconds; RE, right ear.

$¥:$ T-Student Test for independent groups; $¥:$ Mann Whitney U Test. Level of statistical significance: $p<0.05$.

This research showed no statistical significance of the amplitude values of the MMN between gender ( - Table 3 and - Fig. 2). The mean amplitude in the female group was $4.1 \mu \mathrm{V}$ in the RE and $4.4 \mu \mathrm{V}$ in the $\mathrm{LE}$, and for in male group it was $5.1 \mu \mathrm{V}$ in the RE and $3.9 \mu \mathrm{V}$ in the LE. These results corroborate with a previous research ${ }^{1}$ that also did not find significant statistical differences between the gender for the amplitude and obtained similar results to this study. The mean amplitude was $3.548 \mu \mathrm{V}$ in the RE and $2.757 \mu \mathrm{V}$ in the LE for the female group and $1.867 \mu \mathrm{V}$ in the $\mathrm{RE}$ and $1.435 \mu \mathrm{V}$ in the $\mathrm{LE}$ for the male group.

Some studies ${ }^{27,32,33}$ demonstrated neurophysiological differences between gender, particularly for verbal abilities in favor of women. Research ${ }^{27,32,33}$ indicates that, in general, the amplitude of MMN is greater in women than in men, whereas the latency is greater in men. Nevertheless, these differences occur only for stimuli with phonemics contrasts. The women have more sensitivity to detect the differences in the temporal spectrum of sound, which are related to auditory discrimination of phonemic contrasts. ${ }^{1,27}$

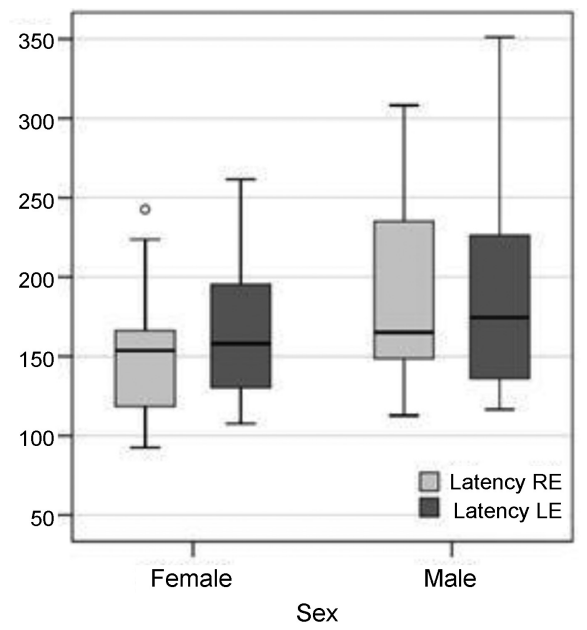

Although in this study the stimulus used for the MMN was a tonal stimulus with frequency contrast, the difference between gender is visible for the RE. In addition, in another study ${ }^{1}$ similar to this, the mean latency in male individuals also showed to be increased in relation to female for tonal stimuli, in both ears (-Table 2). Based on the present study, we can infer that women may be more favored in relation to auditory discrimination and processing of non-verbal sounds in the right ear. Thus, gender may be a factor that influences the development of normative data in studies with cognitive electrophysiological tests, such as the MMN.

Despite some controversy, there are studies that consider the left-brain hemisphere responsible for the analysis of linguistic sounds, while the right brain hemisphere is considered responsible for decoding non-linguistic sounds, such as musical and rhythmic sounds. ${ }^{20,34}$ As a consequence of the left hemispheric dominance for language processing, a great part of the individuals are better in the attention to the stimuli heard by the right ear, due to the

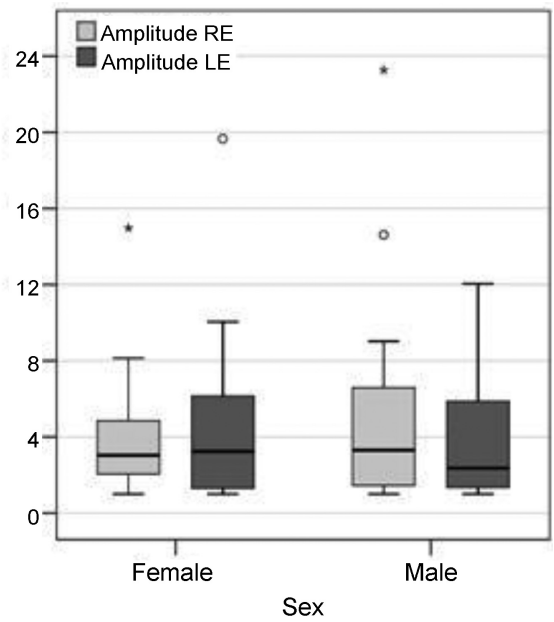

Fig. 2 Box-Plot. Distribution of amplitude and latency values in both ears according to gender. Abbreviations: LE, left ear; RE, right ear. 
Table 4 Comparison for latency and amplitude of MMN according to hand dominance and ear

\begin{tabular}{|c|c|c|c|c|c|c|}
\hline \multirow{2}{*}{\multicolumn{2}{|c|}{ Hand dominance variables }} & \multicolumn{5}{|c|}{ Descriptive measures $(n=40)$} \\
\hline & & Mean value & Standard deviation & Minimum & Maximum & $\mathrm{p}$ \\
\hline \multicolumn{7}{|l|}{ Latency (ms) } \\
\hline \multirow[t]{2}{*}{ Right-handed } & Lat RE & 164.7 & 51.3 & 92.5 & 308.2 & \multirow[t]{2}{*}{$0.213 €$} \\
\hline & Lat LE & 172.0 & 53.4 & 107.6 & 351.1 & \\
\hline \multirow[t]{2}{*}{ Left-handed } & Lat RE & 211.1 & 36.0 & 159.4 & 242.6 & \multirow[t]{2}{*}{$0.781 \S$} \\
\hline & Lat LE & 205.4 & 57.3 & 127.8 & 261.5 & \\
\hline \multirow[t]{2}{*}{ Lat RE } & Right-handed & 164.7 & 51.3 & 92.5 & 308.2 & \multirow[t]{2}{*}{$0.021 ¥$} \\
\hline & Left-handed & 211.1 & 36.0 & 159.4 & 242.6 & \\
\hline \multirow[t]{2}{*}{ Lat LE } & Right-handed & 172.0 & 53.4 & 107.6 & 351.1 & \multirow[t]{2}{*}{$0.035 ¥$} \\
\hline & Left-handed & 205.4 & 57.3 & 127.8 & 261.5 & \\
\hline \multicolumn{7}{|l|}{ Amplitude $(\mu \mathrm{V})$} \\
\hline \multirow[t]{2}{*}{ Right-handed } & Amp RE & 4.5 & 4.7 & 1.0 & 23.3 & \multirow[t]{2}{*}{$0.213 E$} \\
\hline & Amp LE & 4.0 & 4.0 & 1.0 & 19.7 & \\
\hline \multirow[t]{2}{*}{ Left-handed } & Amp RE & 5.2 & 1.6 & 4.3 & 7.6 & \multirow[t]{2}{*}{$0.587 \S$} \\
\hline & Amp LE & 6.0 & 1.1 & 4.6 & 6.9 & \\
\hline \multirow[t]{2}{*}{ Amp RE } & Right-handed & 4.5 & 4.7 & 1.0 & 23.3 & \multirow[t]{2}{*}{$0.755 ¥$} \\
\hline & Left-handed & 5.2 & 1.6 & 4.3 & 7.6 & \\
\hline \multirow[t]{2}{*}{ Amp LE } & Right-handed & 4.0 & 4.0 & 1.0 & 19.7 & \multirow[t]{2}{*}{$0.361 ¥$} \\
\hline & Left-handed & 6.0 & 1.1 & 4.6 & 6.9 & \\
\hline
\end{tabular}

Abbreviations: $\mu \mathrm{V}$, microvolt; Amp, amplitude; Lat, latency; LE, left ear; ms, milliseconds; RE, right ear.

$¥:$ Test t-Student for independent groups; $¥:$ Mann Whitney U Test; $€$ : T-Student Test for paired data; $§$ : Wilcoxon Test. Level of statistical significance: $p<0.05$.

contralateral pathway directing to the left brain hemisphere. $^{35,36}$

In this study, hand dominance was considered a reference for the brain hemisphere dominance in each individual and, therefore, one of the objectives was to investigate if there was any difference in the MMN latencies and amplitudes in the ears of right- and left-handed individuals ( - Table 4 ).

The primary hypothesis of this study was that non-verbal sounds, like the tone stimuli used in this survey, heard by the left ear of right-handed individuals, could present lower latencies in relation to the right ear. Thus, the stimulus heard by the left ear would be directed to and processed more quickly by the right brain hemisphere, which seems to be more specialized in decoding non-linguistic sounds. Other studies have already demonstrated that, for tone stimuli, the left ear has shorter latencies than the right ear. ${ }^{27}$ However, given the results ( - Table 4 ), this assumption could not be confirmed because, although there was no statistical difference between the ears, the LE had longer latencies compared with the RE in right-handed individuals.

On the other hand, researchers have already mentioned that, for left-handed subjects, the right brain hemisphere indicates greater activation for linguistic sound processing, differently from what has been observed in right-handed individuals. ${ }^{37}$ Thus, the authors of the present study hypothesize that the left-handed individuals could process the tone stimulus heard by the RE with a shorter latency compared with the LE, because it would reach the left hemisphere more quickly, which could demonstrate more ability for nonlinguistic sounds for the left-handers. Given the results (-Table 4), these hypotheses were not observed in this research for both latency and amplitude. However, the results showed that latency in the LE was higher for the left-handers than the right-handers. These results allow one to infer that the right-handers are quicker in decoding and processing non-verbal sounds heard by the LE compared with the lefthanders, due to the lateral activation of the right brain hemisphere. The present authors consider that there should be more research papers addressing the MMN in left- and right-handers, to verify possible differences between these individuals.

Furthermore, the results from this study are important to consider that the MMN could be a useful tool for the detection of central auditory disorders. The normative values found in this research contributes to the literature and allows the clinician to have references of values of MMN.

\section{Conclusion}

It was possible to obtain references of values for the MMN. There are no differences in the MMN latencies and amplitudes between ears. The male individuals showed increased latencies compared with female individuals in the right ear. Moreover, the results indicated that there was difference in the MMN latencies for the right and left-handed individuals when comparing between ears. 


\section{References}

1 Brossi AB, Borba KC, Garcia CFD, Reis ACMB, Isaac MdeL. Verification of the Mismatch Negativity (MMN) responses in normal adult subjects. Braz J Otorhinolaryngol 2007;73(6):793-802

2 Matas CG, Hataiama NM, Gonçalves IC. Estabilidade dos potenciais evocados auditivos em indivíduos adultos com audição normal. Rev Soc Bras Fonoaudiol 2011;16(1):37-41

3 ASHA. American Speech-Language Hearing Association. Guidelines for Competencies in Auditory Evoked Potential Measurement and Clinical Applications. Available at: http://www.asha.org/ policy/KS2003-00020/. Accessed May 04, 2015

4 Reis ACMB, Frizzo ACF. Potencial Evocado Auditivo Cognitivo. In: Boéchat EM, Menezes PL, Couto CM, Frizzo ACF, Scharlach RC, Anastásio ART, eds. Tratado de Audiologia. São Paulo, Brazil: Santos; 2015:140-150

5 Sleifer P. Avaliação eletrofisiológica da audição em crianças. In: Cardoso MC (Org.). Fonoaudiologia na infância: avaliação e tratamento. Rio de Janeiro, Brazil: Revinter; 2015:171-194

6 Shiga T, Yabe H, Yu L, et al. Temporal integration of deviant sound in automatic detection reflected by mismatch negativity. Neuroreport 2011;22(7):337-341

7 Roggia SM. Mismatch Negativity. In: Boéchat EM, Menezes PL, Couto CM, Frizzo ACF, Scharlach RC, Anastásio ART, eds. Tratado de Audiologia. São Paulo, Brazil: Santos; 2015:151-159

8 Näätänen R, Astikainen P, Ruusuvirta T, Huotilainen M. Automatic auditory intelligence: an expression of the sensory-cognitive core of cognitive processes. Brain Res Brain Res Rev 2010;64(1): 123-136

9 Soares AJC, Sanches SGG, Lobo IFN, Carvallo RMM, Matas CG, Cárnio MS. Potenciais evocados auditivos de longa latência e processamento auditivo central em crianças com alterações de leitura e escrita: Dados preliminares. Arq Int Otorrinolaringol (Impr.) 2011;15(4):486-491

10 Roggia SM, Colares NT. O mismatch negativity em pacientes com distúrbios do processamento auditivo (central). Rev Bras Otorrinolaringol (Engl Ed) 2008;74(5):705-711

11 Rocha-Muniz CN, Befi-Lopes DM, Schochat E. Mismatch negativity in children with specific language impairment and auditory processing disorder. Braz J Otorhinolaryngol 2015;81(4): 408-415

12 Näätänen R, Kujala T, Kreegipuu K, et al. The mismatch negativity: an index of cognitive decline in neuropsychiatric and neurological diseases and in ageing. Brain 2011;134(Pt 12): 3435-3453

13 Kaser M, Soltesz F, Lawrence P, et al. Oscillatory underpinnings of mismatch negativity and their relationship with cognitive function in patients with schizophrenia. PLoS ONE 2013;8(12): $1-11$

14 Silva DRO, Carnaúba ATL, Bastos FRA, Andrade MMGB, Andrade KCL, Menezes PL. Mismatch negativity (MMN) e P300 em pacientes com esquizofrenia e com experiências alucinógenas auditivas. Distúrb Comun 2015;27(1):193-195

15 Näätänen R. Mismatch negativity: clinical research and possible applications. Int J Psychophysiol 2003;48(2):179-188

16 Santos MAR, Munhoz MSL, Peixoto MAL, Haase VG, Rodrigues JL, Resende LM. Contribuição do mismatch negativity na avaliação cognitiva de indivíduos portadores de esclerose múltipla. Rev Bras Otorrinolaringol (Engl Ed) 2006;72(6): 800-807

17 Buranelli G, Barbosa MB, Garcia CF, et al. Mismatch Negativity (MMN) response studies in elderly subject. Braz J Otorhinolaryngol 2009;75(6):831-838
18 Freigang C, Rübsamen R, Richter N. Pre-attentive cortical processing of behaviorally perceptible spatial changes in older adults-a mismatch negativity study. Front Neurosci 2014; 8(146):1-10

19 Zora H, Schwarz IC, Heldner M. Neural correlates of lexical stress: mismatch negativity reflects fundamental frequency and intensity. Neuroreport 2015;26(13):791-796

20 Garrido MI, Kilner JM, Stephan KE, Friston KJ. The mismatch negativity: a review of underlying mechanisms. Clin Neurophysiol 2009;120(3):453-463

21 Restuccia D, Zanini S, Cazzagon M, Del Piero I, Martucci L, Della Marca G. Somatosensory mismatch negativity in healthy children. Dev Med Child Neurol 2009;51(12):991-998

22 Davis H, Silverman RS. Hearing and deafness. Nova York, NY: Holt, Rinehart \& Winston; 1970:522

23 Jerger J. Clinical experience with impedance audiometry. Arch Otolaryngol 1970;92(4):311-324

24 Neves IF, Schochat E. Maturação do processamento auditivo em crianças com e sem dificuldades escolares. Pró Fono R Atual Cient 2005;17(3):311-320

25 Cooray GK, Garrido MI, Brismar T, Hyllienmark L. The maturation of mismatch negativity networks in normal adolescence. Clin Neurophysiol 2015;127:1-10

26 Veras RP, Mattos LC. Audiologia do envelhecimento: revisão de literatura e perspectivas atuais. Rev Bras Otorrinolaringol (Engl Ed) 2007;73(1):128-134

27 Ikezawa S, Nakagome K, Mimura M, et al. Gender differences in lateralization of mismatch negativity in dichotic listening tasks. Int J Psychophysiol 2008;68(1):41-50

28 Ji LL, Zhang YY, Zhang L, He B, Lu GH. Mismatch negativity latency as a biomarker of amnestic mild cognitive impairment in chinese rural elders. Front Aging Neurosci 2015;7(22):1-5

29 Gução ACB. Efeito da variação de freqüência e duração do estímulo no registro do P300 e MMN [masters dissertation]. São Paulo (SP), Brazil: Universidade Estadual Paulista, Faculdade de Filosofia e Ciências de Marília; 2014:28-31. Available at: http://repositorio. unesp.br/handle/11449/110546. Accessed September 27, 2015

30 Didoné DD, Garcia MV, da Silveira AF. Long latency auditory evoked potential in term and premature infants. Int Arch Otorhinolaryngol 2014;18(1):16-20

31 Asano S, Shiga T, Itagaki S, Yabe H. Temporal integration of segmented-speech sounds probed with mismatch negativity. Neuroreport 2015;26(17):1061-1064

32 Voyer D. Sex differences in dichotic listening. Brain Cogn 2011; 76(2):245-255

33 Aerts A, van Mierlo P, Hartsuiker RJ, Santens P, De Letter M. Sex differences in neurophysiological activation patterns during phonological input processing: an influencing factor for normative data. Arch Sex Behav 2015;44(8):2207-2218

34 Silva TR, Dias FAM. Diferenças na habilidade de integração auditiva inter-hemisférica entre os gêneros feminino e masculino: estudo preliminar. Rev Soc Bras Fonoaudiol 2012;17(3):260-265

35 Flöel A, Buyx A, Breitenstein C, Lohmann H, Knecht S. Hemispheric lateralization of spatial attention in right- and lefthemispheric language dominance. Behav Brain Res 2005; 158(2):269-275

36 Mendonça I, Saraiva H, Horácio JLG. A audição dicótica no diagnóstico de dislexia. J Child Adolescent Psychol 2012;3(2): 261-275

37 Cobianchi A, Dall'Armi V, Giaquinto S. An electrophysiological contribution to the study of language lateralization and prognosis of aphasia. Int J Rehabil Res 2010;33(2):134-141 